We try to publish authors' responses in the same edition with readers' comments. Time constraints might prevent this in some cases. The problem is compounded in a bimonthly journal where continuity of comment and redress are difficult to achieve. When the redress appears 2 months after the comment, 4 months will have passed since the article was published. Therefore, we would suggest to our readers that their correspondence about published papers be submitted as soon as possible after the article appears.

\section{Use of Drug Sample Medications}

To the Editor: I read with interest and some concern the article by Zweifler et al in the 2002 September-October issue of the $7 A B F P$ (Zweifler J, Hughes S, Schafer S, et al. Are Sample Medications Hurting the Uninsured? J Am Board Fam Pract 2002; 15:361-6). The only conclusion I reach after reading the study is that we still do not know and that this study has added little to our knowledge.

I will state my bias at the onset. I give out sampleslots of them-to my Medicare patients without medication coverage and to my uninsured patients, as well as to some of my insured patients who are on so much medicine as to make even the co-payments prohibitive. I realize doing so is much easier in my private solo practice than it would be in a large clinic. Therein lies my first objection-the data are not necessarily generalizable.

In addition, it appears patients using samples were required to have a follow-up appointment to get more supplies. This financial cost to the uninsured patient would be expected to be prohibitive, even if a sliding scale were offered. A fairer way to compare the effect of using sample medications with outcomes from filling prescription medications would be to allow patients to call in for "refills" of samples without the need to be seen. We do this frequently at my office with good results. Patients are less likely to be noncompliant (and thus have higher blood pressures). The medication outcomes will not be evenly comparable, because some patients are embarrassed to come to the office frequently to pick up their samples, but it makes any comparison fairer.

Finally, I believe we are looking at divergent groups of patients in this study. I would expect samples to be given to the poorest and the sickest patients. Both these groups are more likely to have worse disease. Comparing these patients with patients who have insurance (or with money) is comparing apples with oranges. In fact, the only fair (and useful) way to compare these two groups of patients is to observe the patients taking the samples but to stop providing the samples and write prescriptions instead. A comparison of this nature, where patients act as their own controls, is the only reasonable way to determine whether the provision of samples is the true evil this article leads one to believe.
I understand the concern raised by free samples provided to physicians and their patients. Certainly these samples are of the more costly drugs and ultimately will affect our prescribing habits and the cost to our patients. In fairness, however, there are some patients who truly benefit from samples, and there are ways of using samples, short term, then switching to an equivalent generic medication (eg, switching from Toprol XL to metoprolol, or from Accupril to lisinopril). Before we throw the baby out with the bath water, I believe we need far more solid evidence of harm caused by samples than we gain from this study.

Wayne S. Strouse, MD

Pen Yan, NY

The above letter was referred to the authors of the article in question, who offer the following reply.

To the Editor: Thanks to Dr. Strouse for his thoughtful review of our work. We are in agreement with almost all his themes. It seems important to reiterate that ours was primarily a cross-sectional design, and that we make no claims of a causal relation between sample medication provision and higher blood pressure. This explanation would, of course, represent only one of many plausible reasons, including chance variation. As Dr. Strouse suggests, another possibility is that our study is simply a snapshot of physicians responding appropriately to poorly controlled blood pressure by using every means possible to provide medication for uninsured patients. In fact, much current evidence tells us that the simple condition of lacking health insurance is itself associated with less favorable chronic disease status. ${ }^{1-3}$

While our study admittedly only begins to explore the relation between insurance status, sample medication use, and hypertension, there is some existing indirect evidence that different physician prescribing habits and access to medication might represent one pathway that links lack of insurance and poor health. ${ }^{2,4,5}$ Resolution of these questions awaits a prospective trial, as Dr. Strouse correctly suggests. Meanwhile, the contribution of our study is to remind us all that we cannot simply assume that the availability and the use of free sample medicines improve blood pressure in the uninsured. It also seems salient to note that the modest literature currently available on this subject suggests the availability of free samples is associated with less frequent use of first-line agents for hypertension ${ }^{6}$ and higher prescribing costs. ${ }^{7}$

Finally, Dr. Strouse offers his own suggestions for effective use of sample medication, including a description of his own practice of "refilling" sample medicines by telephone. This idea seems to belie the inherent temporary and unpredictable availability of costly new medicines left on a physician's shelf by pharmaceutical 
representatives, whose principle goal is sales. Moreover, we do not have any data to suggest that his customs are widespread. The only article we found on this topic ${ }^{8}$ suggests that attitudes and practices toward pharmaceutical samples vary widely across practices and that the lack of a coherent policy or approach is the norm. We believe that Dr. Strouse is largely correct in assuming our patients had to make an additional visit to collect additional sample medication supplies, but doing so was not a condition of participation. The only additional insight our data provided into this issue was the lack of a significant association between self-reported compliance and the sample medication status.

Sean Schafer, MD

John Zweifler, MD, MPH

Susan Hughes, MS

UCSF-Fresno Family Practice Residency Program Fresno, Calif

\section{References}

1. Moy E, Bartman BA, Weir MR. Access to hypertensive care. Effects of income, insurance, and source of care. Arch Intern Med 1995;155;1497-502.

2. Becker G. Effects of being uninsured on ethnic minorities' management of chronic illness. West J Med 2001;175: $19-23$.

3. Baker DW, Sudano JJ, Albert JM, Borawski EA, Dor A. Lack of health insurance and decline on overall health in late middle age. $\mathrm{N}$ Engl J Med 2001;345:1106-12.

4. Kalb JL, Marazon DJ, Snow RJ. Potential barriers to control of blood pressure. J Am Osteopath Assoc 2002;102: 209-13.

5. Berlowitz DR, Ash AS, Hickey EC, et al. Inadequate management of blood pressure in a hypertensive population. N Engl J Med 1998;339:1957-63.

6. Boltri JM, Gordon ER, Vogel RL. Effect of antihypertensive samples on physician prescribing patterns. Fam Med 2002; 34: 729-31.

7. Caudill TS, Johnson MS, Rich EC, McKinney WP. Physicians, pharmaceutical sales representatives, and the cost of prescribing. Arch Fam Med 1996;5:201-6.

8. Backer EL, Lebsack JA, Van Tonder RJ, Crabtree BF. The value of pharmaceutical representative visits and medication samples in community-based family practices. J Fam Pract 2000;49:811-6.

\section{Sample Medications and the Uninsured}

To the Editor: I am a family physician and recently completed residency in an underserved area. I am responding to an article in the September-October issue of the $7 A B F P$ (Zweifler J, Hughes S, Schafer S, et al. Are Sample Medications Hurting the Uninsured? J Am Board Fam Pract 2002; 15:361-6).

To suggest that sample medications are harmful to patients is insulting to the physicians who work in underserved areas. I have had patients with multiple medical problems whose only competition for their unpleasant lot in life was their lack in funding. Their richness in medical illness was supported by their poverty. For these patients, the generosity of drug companies to leave medications in areas where they knew few if any patients would be able to pay for the medications was admirable. For months I was able to control blood pressure and diabetes in patients who would have otherwise succumbed to the tragedies of their disease.

This article shows an insensitivity to the physicians who serve patients with limited funds. These same patients, who would otherwise be adding to worsening morbidity and mortality statistics, take theses sample medications instead and keep their illnesses at bay. I agree that these patients deserve better care, but there are no funds to pay for such care, and the patients and physicians do what patients and physicians have done for centuries. . . the best they can.

Melissa J. Hubbard, MD
Austin Regional Clinic
Austin, Texas

\section{Canadian Health Care System}

To the Editor: I read with interest your informative article on family practice in a failing health care system in the September-October 2002 issue of the $7 A B F P$ (Geyman JP. Family Practice in a Failing Health Care System: New Opportunities to Advocate for System Reform. J Am Board Fam Pract 2002;15:407-15).

I trained in family practice in Ohio and have practiced in Ohio and Ontario, Canada. I wrote to your journal a few years ago to explain what I perceived as advantages to health care system in Canada. Since then, however, our universal method has showed increasing problems and deficiencies and is under increasing attack by the Canadians.

When the single-payer system established itself in Canada in the 1960s, the timing could not have been better. It was embraced by patients and health care providers alike. At that time, available medical technologies were much less advanced, and government monies could afford the cost for nearly everyone. (With the United States providing us military defense free of charge, our publically funded health care delivery model was second to none.)

Today is a different story. Waiting lists for testing and specialty care are the norm. The Canadians are more aware of what is available to private patients in the United States, and they expect the same in Canada, which is impossible in a publically funded system.

There is still something appealing and respectable about a universal system, even as it shows its flaws. (This observation might be irrational coming from a Canadian who is hopelessly proud of the last remaining institution that defines Canada as being different from America.) I admire the physicians and subspecialists with whom I work in Canada. The pull of America is always evident, but many prefer to stay because they believe they provide sound care for their patients. "Coverage for all" might still be approachable with proper changes and the insertion of a private element. Opening the doors to more well-trained foreign physicians would also help Canada.

America needs to take a different approach. Without a previous template, a universal single-payer system can- 
not be built in this day and age. (For one thing, too many persons would lose their jobs.)

The United States would be better off making its private insurers and $\mathrm{HMOs}$ more accountable to the consumer and large employers who pay into them. They should explain large bonuses and extra costs to the consumer or suffer the consequences. Put them under intense scrutiny, like Enron and WorldCom and the rest. If government regulators can realize that the health care consumer is at a bigger disadvantage than any other consumer (ie, they are sick or have a condition), then the United States can have compassionate health care delivery with the advantage of American know how and resources. It would be a win-win situation.

George D. Strelioff, MD Richmond Hill, Ontario 